\title{
The Risk-Based Floodplain Regulation of Shiga Prefecture in Japan
}

\author{
Satoru Ichidate ${ }^{1 a}$, Mitsuhiro Tsuji ${ }^{1}$, Kentaro Taki $^{1}$ and Hitoshi Nakamura ${ }^{2}$ \\ 1 Shiga Prefectural Government, 4-1-1 Kyo-machi, Otsu, Shiga 520-8577, Japan \\ 2 Shibaura Institute of Technology, 307 Fukasaku, Minuma-ku, Saitama-shi, Saitama 337-8570, Japan
}

\begin{abstract}
This study shows the overview of the risk-based floodplain regulation implemented by the Shiga Prefectural Government. Shiga, located near Kyoto in central Japan, is home to Lake Biwa, the largest lake in the country. Approximately 500 rivers flow into Lake Biwa from the steep surrounding mountains. The population is concentrated in alluvial cones and alluvial plains. The Shiga Prefectural Government enacted the integrated flood management ordinance in March 2014. This ordinance includes land use and building regulation measures in order to promote flood risk reduction for excessive flood events based on the newly developed risk evaluation method, which is the first in Japan. The goal of the risk-based floodplain regulation is to make use of existing legal framework for effective land use and building regulations, based on comprehensive flood hazard risk maps, to indicate both the damage levels and occurrence probabilities of various floods at all sites in a flood plain.
\end{abstract}

\section{Introduction}

Shiga, located near Kyoto in central Japan, is home to Lake Biwa, the largest lake in the country. Lake Biwa is $670 \mathrm{~km} 2$, occupying one-sixth of the entire prefecture. Approximately 500 rivers flow into Lake Biwa from the steep surrounding mountains. The length of most of these rivers is shorter than $50 \mathrm{~km}$. There are 81 "tenjou" rivers with beds above the mean ground level. The population is concentrated in alluvial cones and alluvial plains.

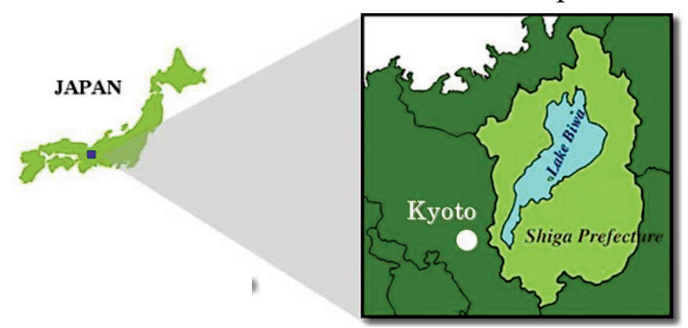

Figure 1. Location of Shiga Prefecture.

The occurrence of floods beyond the design scale or capacity of conventional flood control measures will be inevitable due to climate change. The Shiga Prefectural Government made the basic policy for river basin management in 2012, and enacted the integrated flood management ordinance in March 2014. This ordinance includes land use and building regulation measures in order to promote flood risk reduction for excessive flood events, based on the newly developed risk evaluation method, which is the first in Japan.

This study shows the overview of the risk-based floodplain regulation implemented by the Shiga Prefectural Government focusing on land use and building regulation measures.

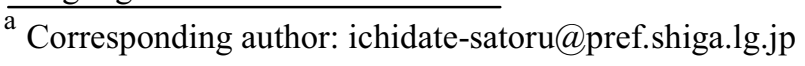

\section{Flood plain management in Shiga}

Flood plain management plays an important role in reducing potential damage involving casualties. The principle objective of the basic policy for river basin management in Shiga is to prevent any loss of human life, as well as severe damage from inundation above the ground floor of a residential building in excessive flood events. It consists of four basic measures: discharge measures, retention measures, flood plain management measures, and other non-structural measures. Discharge measures include embankments and channel excavations. Retention measures include retention ponds and flood prevention reservoirs. Flood plain management measures include riparian forests, secondary dikes, and land use and building regulations. Other non-structural measures include evacuation systems, disaster response drills, education, and risk communications. In this study, we focus on land use and building regulations as the significant flood plain management measures.

From a historical viewpoint, elevation of the site or the ground floor of a building had been commonly conducted in areas affected by floods in the past. However, in recent years, due to the reduction of serious flood inundation by the progress of structural measures against the certain design size floods, many buildings have been constructed in high risk areas. Taking into consideration the effect of climate change, it is important to disseminate appropriate flood risk information in order to raise the awareness of local people and to introduce effective land use and building regulations for excessive flood events. 
According to the legal precedent of the Constitution of Japan, the ordinance enacted by a local government is not allowed to regulate property rights if a national law that has the same objective has already been established.

Regarding land use regulations, the Urbanization Promotion Area and the Urbanization Control Area can be stipulated by the City Planning Law. According to the circular notice by the Ministry of Construction in 1970, the area whose estimated inundation depth is higher than $50 \mathrm{~cm}$ (inundation above ground floor level), in the event that the precipitation intensity is about $50 \mathrm{~mm}$ in one hour, (in about a 10 year flood) should be prohibited from inclusion in the Urbanized Promotion Area. Outside of the Urbanized Promotion Area, the construction of buildings is strictly regulated by the Law. However, because appropriate information to indicate the inundation estimation for the regulation has not been developed, this circular notice has not been effectively used until today.

Regarding building regulations, according to Article 39 of the Building Standards Law, a Disaster Risk Reduction Priority District can be designated by the local government for natural disaster high-risk areas. In the Disaster Risk Reduction Priority District, the construction of buildings is strictly regulated. The circular notice by the Ministry of Construction in 1959 clarified the regulation standards based on the inundation depth and fluid force. However, all Disaster Risk Reduction Priority Districts have been designated only after the relevant disaster occurred in order to prevent the same damage for the future. Because appropriate information about flood risk has not been developed, this circular notice has not been effectively used for prevention measures.

Therefore, it is necessary to develop an effective method to evaluate flood hazard risk to provide a basis for land use and building regulations.

\section{Methodology for evaluating flood hazard risk}

The Shiga Prefectural Government developed a numerical model to calculate flood risk by dividing Shiga Prefecture into $50 \mathrm{~m} \times 50 \mathrm{~m}$ grids $[1,2]$. A drainage model was introduced to predict rainfall run-off, channel flows, and overtopping or breach flow processes on a flood plain. This numerical model considers flood flows not only from large rivers (mainly "tenjou" rivers with beds above the mean ground level) but also from agricultural water channels and small networks of drainage canals (Figure 2).

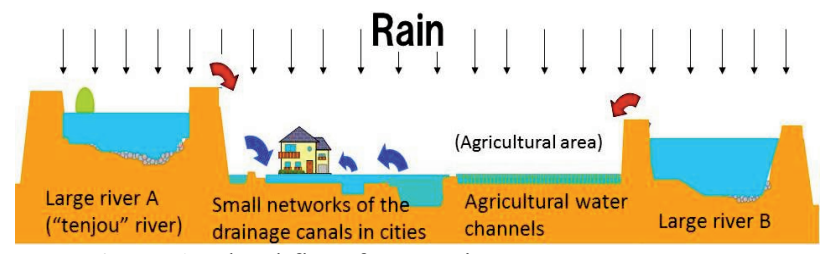

Figure 2. Flood flow from various sources.

A drainage basin model (Figure 3) was introduced to predict rainfall run-off, channel flows, and overtopping or breach flow processes. The drainage basin was divided into three zones: zone 1 is a mountain area, zone 2 is a river reach with a drainage basin, and zone 3 is the main reach with a flood plain. Channel flow was evaluated both in zones 2 and 3 by means of 1-D governing equations. In the flood plain of zone 3 and in the drainage area of zone 2, depth-integrated 2-D governing equations were employed to predict flow depth, flow velocity, and fluid forces.

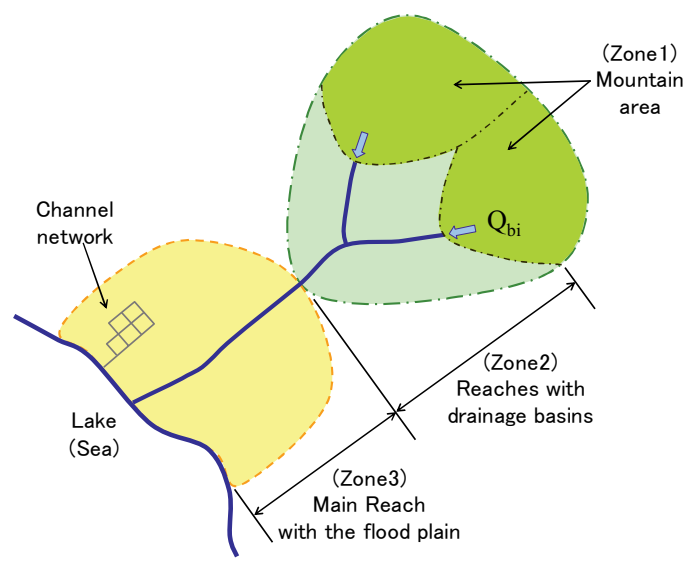

Figure 3. Schematic of drainage basin.

The Shiga Prefectural Government formulated information about the space-time distribution of the various return period floods such as 10, 30, 50, 100, 200, 500 , and 1000 years based on rain fall data in the past. Rainfall events with 200-, 500-, and 1000-year return periods were set at $1.2,1.5$, and 1.8 times the rainfall size with a 100 -year return period [3].

Regarding conditions of levee breach [4], three cases were considered: case 1 assumed a levee breach occurring at the same time as the water level exceeds the levee crown, case 2 assumed the breach occurs whenever the water level rises to the bottom level of freeboard below the levee crown, and case 3 assumed no breach with floods exceeding the flow capacity of the channel.

The magnitude of damage can be classified into five levels [5]: level 1 (less than $0.1 \mathrm{~m}$ ) indicates no damage, level $2(0.1 \mathrm{~m}$ to $0.5 \mathrm{~m})$ indicates damage from inundation below the ground floor of a building, level 3 $(0.5 \mathrm{~m}$ to $3.0 \mathrm{~m})$ indicates severe damage from inundation above the ground floor, level 4 (3.0 $\mathrm{m}$ or more than 3.0 $\mathrm{m}$ ) indicates fully submerged, and level 5 (more than 2.5 $\mathrm{m} 3 / \mathrm{s} 2$ ) indicates completely destroyed.

The probability of occurrence of each flood event was evaluated by means of its return period for a rainfall size: $1 / 2,1 / 10,1 / 30,1 / 50,1 / 100,1 / 200,1 / 500$, and 1/1000. Casualty appears from levels 4 and 5 . Figure 4 shows the probability of inundation above the ground floor (level 3). 


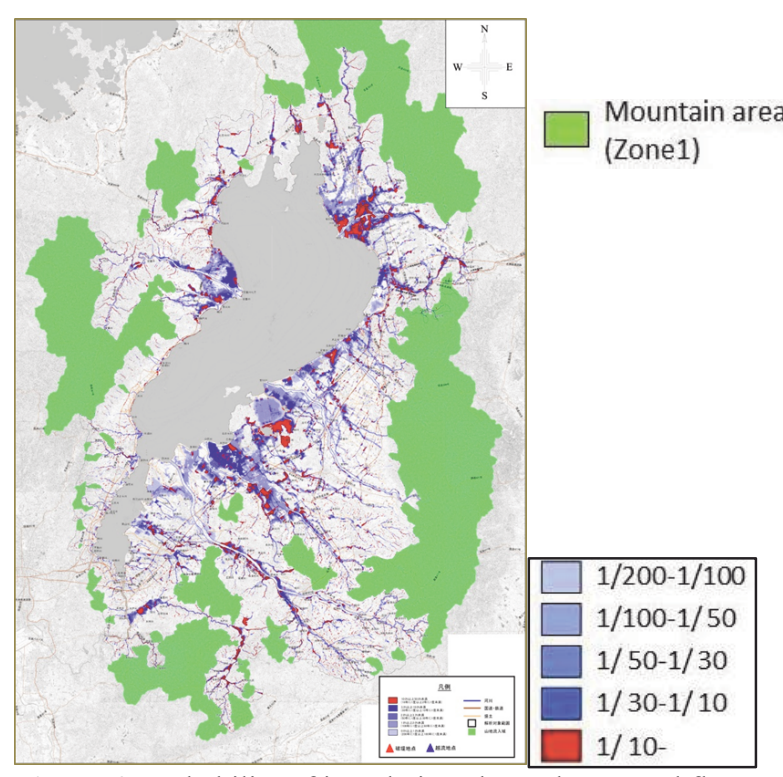

Figure 4. Probability of inundation above the ground floor on the flood hazard risk map.

By computing the rainfall run-off and inundation process, the flood hazard risk of each mesh point will be specified in terms of matrix element (Figure 5). The rows of the matrix correspond to the occurrence probabilities of various floods based on 8 rainfall sizes. The columns indicate flood damage levels from 1 to 5 . The risk matrix provides flood hazard risk maps reflected by flood risk at all mesh points in a flood plain. The flood hazard risk maps based on various rainfall events give useful information for promoting suitable land use.

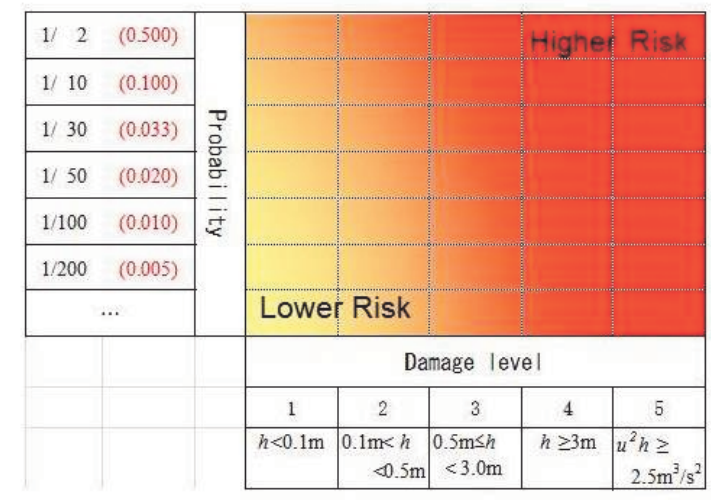

Figure 5. Risk matrix.

\section{Land use and building regulation measures}

Under the current legal structure of the City Planning Law and the Building Standards Law in Japan, the Shiga Prefectural Government enacted the Shiga Integrated Flood Management Ordinance to provide a legal guide to suitable land use and waterproof buildings in order to reduce flood damages. In particular, the areas whose estimated inundation depth is higher than $50 \mathrm{~cm}$ (more than level 3) in a 10 year flood are prohibited from inclusion in the urbanized promotion area stipulated by the City Planning Law. Figure 6 shows the area for land use regulations in the risk matrix.

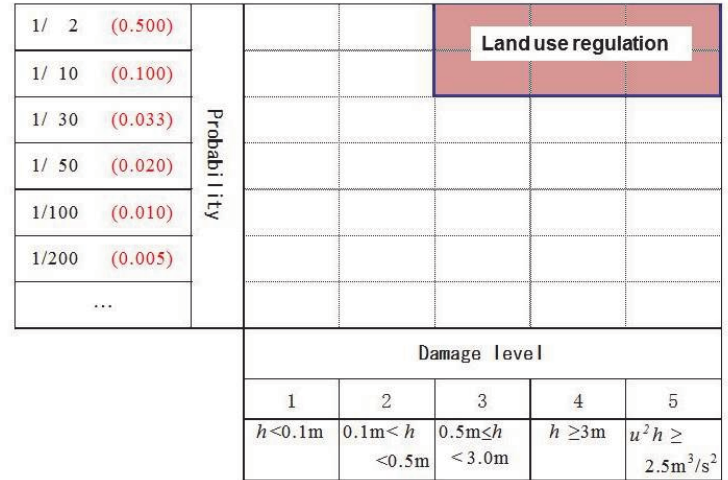

Figure 6. Land use regulation area in the risk matrix.

According to the ordinance, based on Article 39 of the Building Standards Law, the prefectural governor is endowed with the right to designate a Flood Risk Reduction Priority District for the areas whose estimated inundation depth is greater than $3 \mathrm{~m}$ (level 4) in a 200 year flood. Figure 7 shows the area for building regulations in the risk matrix. Figure 8 shows the Level 4 area on the flood hazard risk map.

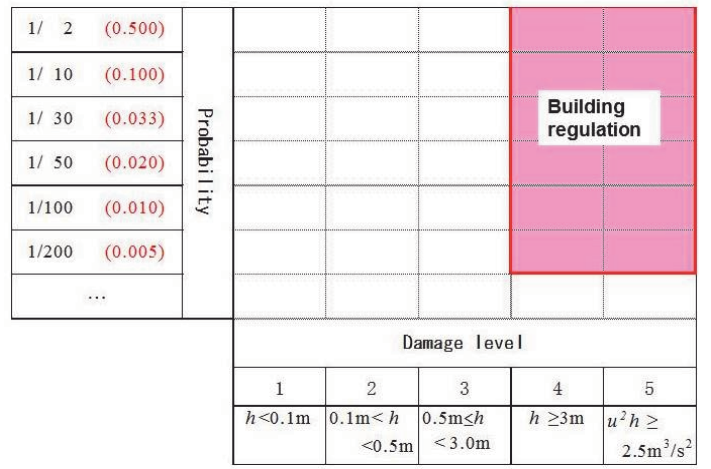

Figure 7. Building regulation area in the risk matrix.

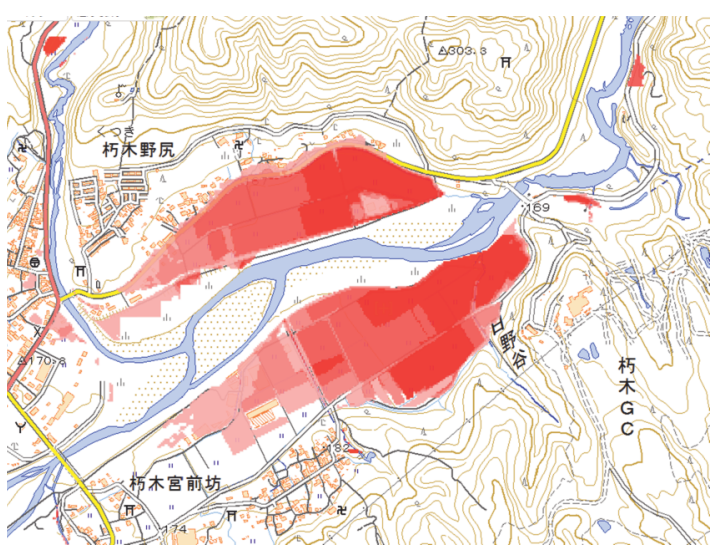

Figure 8. Level 4 area on the flood hazard risk map.

Because this designation requires a community consensus in the area, the prefectural administrative staff is promoting community meetings and workshops for consensus building in several nominated districts. After the designation, the governor has the right to check the waterproof structures with elevation of the ground level of a site or the ground floor of a building, or to create a safe evacuation space above estimated inundation level of each house scheduled for construction in the area (Figure 
9). People who construct a new building to obey the regulations can obtain a subsidy from the prefectural government. For example, in the case of elevating the ground level or floor level, a half of total elevation cost can be covered by the subsidy on the condition that the maximum amount is 2 million yen.

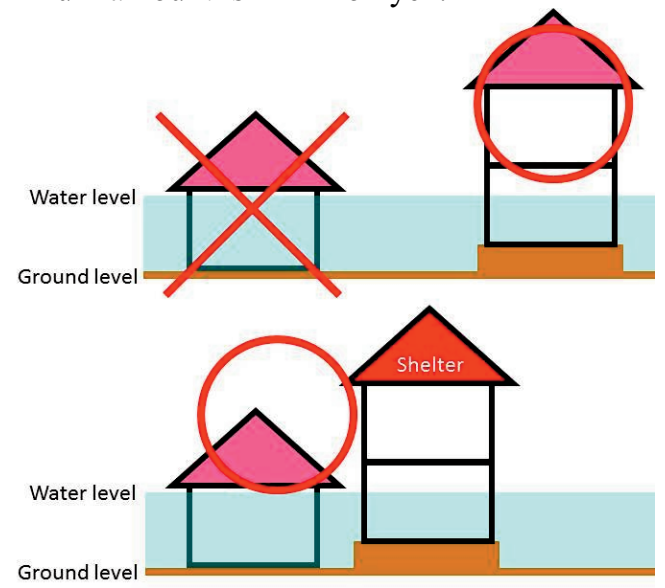

Figure 9. Building regulations in a Flood Risk Reduction Priority District

\section{Conclusions}

The characteristic of the risk-based floodplain regulation implemented by the Shiga Prefectural Government is to make use of existing legal frame for effective land use and building regulations, based on the comprehensive flood hazard risk maps indicating both the damage levels and occurrence probabilities of various floods at all sites in a flood plain.

There are some challenges to be considered to promote these measures.

Building regulations based on Article 39 of the Building Standards Law requires the threshold level for the regulation. According to the Shiga Integrated Flood Management Ordinance, the building whose estimated inundation depth is higher than $3 \mathrm{~m}$ is regulated strictly, while the building whose estimated inundation depth is lower than $3 \mathrm{~m}$ is not regulated at all. In terms of regulations, the $3 \mathrm{~m}$ mark of inundation depth is significant, although the level of flood risk is continuous. This tends to make it difficult to build consensus among local people when designating a Flood Risk Reduction Priority District. A new building regulation system without a threshold level of flood risk should be considered.

In Shiga Prefecture, there are many rivers with beds above the mean ground level. Those rivers are estimated to cause strong fluid force along the river in the event of a levee breach. In the Shiga Integrated Flood Management Ordinance, building regulations based on fluid force more than $2.5 \mathrm{~m} 3 / \mathrm{s} 2$ (level 5) (Figure 10) were intended to be introduced. However, they have not been introduced, because the evaluation of fluid force has not been reliable enough for the basis of regulation. Further research about fluid force is necessary.

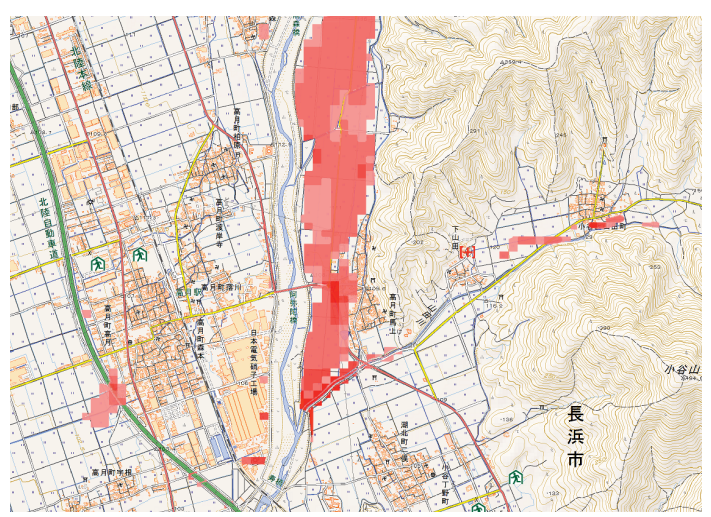

Figure 10. Level 5 area on the flood hazard risk map.

The Shiga Integrated Flood Management Ordinance stipulated the obligation that real-estate agencies should make efforts to give their customers appropriate flood risk information prior to a real-estate transaction. In terms of flood insurance, however, there is no policy for promoting the positive link between the comprehensive flood hazard risk maps and an existing flood insurance system. The only thing that the Shiga Prefectural Government has done so far is to ask some insurance companies to give their customers flood risk information for an insurance contract. Since flood insurance plays a significant role for the recovery from flood damage, an effective policy for promoting flood insurance in relation to the comprehensive flood hazard risk maps should be considered.

\section{References}

1. Taki K., Matsuda T., Ukai E., Nishijima T. and Egashira S. (2013). Method for evaluating flood disaster reduction measures in alluvial plains, Journal of Flood Risk Management, 6, 210-218

2. Taki K., Matsuda T., Ukai E., Fujii S., Kageyama T. and Egashira S. (2009). Study of the evaluation method for flood disaster-reduction measures considering excessive floods in a floodplain of smallmedium sized rivers, Advances in River Engineering, $15,49-54$. (in Japanese)

3. Takara K. and Takasao T.(1998). Criteria for evaluating probability distribution models in hydrologic frequency analysis, Journal of Hydraulic, Coastal and Environmental Engineering, 393( II -9), 151-160. (in Japanese)

4. Muramoto Y.(1996). Safety of an embankment in the time of a flood and study about the value of the flood control technology, Natural disaster scientific overall study group, No.A-61-5. (in Japanese)

5. Sato S., Imamura S. and Shuto N.(1989). Numerical Simulation of Flood and Damage to Houses - A case of the Yoshida river due to Typhoon No. 8610, Annual Journal of Hydraulic Engineering, JSCE,33, 331-336. (in Japanese) 